\title{
Assessment of lactation stage and breed effect on sheep milk fatty acid profile and lipid quality indices
}

\author{
Vassilia J. Sinanoglou ${ }^{1}$ - Panagiota Koutsouli ${ }^{2}$ • \\ Charalambos Fotakis $^{3}$ - Georgia Sotiropoulou ${ }^{1}$. \\ Dionisis Cavouras ${ }^{4} \cdot$ Iosif Bizelis $^{2}$
}

Received: 15 December 2014 /Revised: 19 April 2015 / Accepted: 4 May 2015 /

Published online: 29 May 2015

(C) INRA and Springer-Verlag France 2015

\begin{abstract}
Information on fatty acid (FA) profile is critical for the production and promotion of sheep milk and derivative dairy products. The presence of the essential $\omega-3$ and $\omega-6$ FA in milk fat as well as other less common FA, like linoleic acid isomers, has gained an increasing interest due to the consumer demand for a healthy diet. This research assesses the FA profile and estimates the lipid quality indices (ratio between hypocholesterolaemic and hypercholesterolaemic fatty acids, peroxidisability index, atherogenic index, and thrombogenic index) of raw milk and cream fat from two indigenous Greek sheep breeds (Karagouniko and Chios) at different lactation stages. Raw milk and cream fat presented a favorable $\omega-6 / \omega-3$ ratio below $4: 1$. Atherogenic and thrombogenic indices of all studied milk fat fluctuated in sufficiently low levels $(<3)$. The FA profile and lipid quality indices in both raw milk and cream samples differed significantly depending more on the lactation stage compared to the breed type. Raw milk fat from late lactation had more beneficial fatty acid profile compared to early and middle lactation stages. Differences among breeds were highlighted when raw milk and cream samples were compared within the same lactation stage. Raw milk and cream fat from Karagouniko breed were characterised by higher $\omega-3$ proportion, lower $\omega-6 / \omega-3$ ratio and lower thrombogenic index value compared to those from Chios breed.
\end{abstract}

Vassilia J. Sinanoglou

v_sinanoglou@yahoo.gr; vsina@teiath.gr

1 Instrumental Food Analysis Laboratory, Department of Food Technology, Technological Educational Institution of Athens, Ag. Spyridonos Street, Aigaleo, 12210 Athens, Greece

2 Laboratory of Animal Breeding and Husbandry, Faculty of Animal Science and Aquaculture, Agricultural University of Athens, Iera odos 75, 11855 Athens, Greece

3 Institute of Biology, Medicinal Chemistry \& Biotechnology, National Hellenic Research Foundation, 48, Vas. Constantinou Ave., 11635 Athens, Greece

4 Medical Image and Signal Processing Laboratory, Department of Biomedical Engineering, Technological Education Institution of Athens, Ag. Spyridonos StreetAigaleo 12210 Athens, Greece 
Keywords Sheep milk - Lactation stages · Breed · Fatty acid composition · Lipid quality indices

\section{Introduction}

The significant involvement of milk and dairy products in relation to human dietary requirements for energy, high-quality protein, essential minerals and vitamins is unquestionable. Among the bioactive constituents of sheep milk, lipids are important due to their high nutritional value and effect in physicochemical, sensory and manufacturing properties of dairy products (Park et al. 2007). Sheep milk contains higher total fat and conjugated linoleic acid (CLA) percentages, compared to other ruminant milk (Haenlein and Wendorff 2006). The fatty acid profile of milk fat is affected by a number of genetic (breed, genotype), physiological (age, stage of lactation, season) and environmental (feeding, grazing) factors as well as their interactions (De La Fuente et al. 2009). The majority of studies in milk lipids has been conducted on cow milk (Arnould and Soyeurt 2009; Roca Fernandez and Gonzalez Rodriguez 2012; Nantapo et al. 2014) focusing primarily on the effect of diet on the fatty acid profile of milk fat. The effect of other factors in milk fat, such as breed or stage of lactation, has been much less studied. In recent years, several studies have investigated the effect of ewe breed on the milk fatty acid profile (Signorelli et al. 2008; Talpur et al. 2009; Mierlita et al. 2011). To our knowledge, extensive analysis of fatty acid profile and lipid quality indices in raw milk and cream fat of indigenous breeds, which are kept in the same flock and receive the same management and diet in relation to their stage of lactation, has not been previously published.

In Greece, the sheep population constitutes $9.21 \%$ of the total EU population (EFSA 2014). There are more than 40 indigenous sheep breeds that are well adapted to soil and climatic conditions of Greece. Among them, Karagouniko and Chios breeds are the most popular Greek sheep races for milk production, with satisfactory productivity and quality characteristics. Karagouniko is the second most numerous breed in Greece, kept in lowland flocks, well adapted under harsh environmental conditions and distinguished for its high milk production. Chios is one of the most important dairy and prolific breed, kept as stall-fed, characterised by higher milk yield and litter size, as well as greater incidence to mastitis susceptibility (Hatziminaoglu et al. 1990). The average litter size of Karagouniko and Chios breeds is approximately 1.4 and 1.8 lambs per ewe respectively and the commercialised animal mean milk yield varies between 140-150 and 180-200 L for the Karagouniko and Chios breeds, respectively (Bizelis et al. 1990; Kominakis et al. 1997).

In this context, the present study aims (a) to evaluate the fatty acid (FA) profile and nutritional value of raw milk and cream fat, derived from two indigenous Greek sheep breeds (Karagouniko and Chios) receiving the same diet and raised under the same handling conditions, (b) to investigate the potential of FA profile and lipid quality indices (LQI) in discriminating raw milk and cream fat of sheep on the basis of breed, (c) to investigate how FA proportions and LQI fluctuate during lactation and (d) to propose appropriate lactation stages and breed, on the basis of FA and LQI, for the collection of milk and the development of dairy sheep industries. 


\section{Materials and methods}

\subsection{Reagents and standards}

Fatty acid methyl esters used as gas chromatography-flame ionisation detection (GC-FID) standard mixtures were Supelco TM 37 Component FAME Mix C4C24, Supelco polyunsaturated fatty acid (PUFA) No.1, Marine Source and conjugated linoleic acid methyl esters standard mixture, all purchased from Sigma Chemical Co (Sigma-Aldrich Company, St. Louis, MO, USA). All solvents used for sample preparation were of analytical grade, and the solvents used for GC analysis were of HPLC grade from Merck (Darmstadt. Germany). All reagents used were of analytical grade and they were purchased from Sigma Chemical Co (Sigma-Aldrich Company, St. Louis, MO, USA).

\subsection{Animals and milk sampling}

The experimental ewes were from Karagouniko $(n=21)$ and Chios $(n=27)$ breeds in their second or third lambing and reared in the premises of the experimental farm of the Agricultural University of Athens under the same diet and management conditions. The diet of ewes was composed of alfalfa hay and concentrate mixture and adjusted according to meet their requirements (maintenance and lactation). In detail, during the whole period of experiment, the diet consisted of $0.4 \mathrm{~kg}$ of alfalfa hay and $0.5 \mathrm{~kg}$ of a basal concentrate mixture plus $1-1.5 \mathrm{~kg}$ of lactation concentrate mixture and was given two times per day. Details concerning the composition and the analysis of the diets are shown in Table 1. Water was available ad libitum. Milk production, milk fat content and body mass were recorded weekly. The experiment was carried out from January to June 2013 when the lactation of ewes was completed to avoid the extremely hot conditions that occur in Greece during July and August. The ewes were milked two times daily by milking machine after weaning (42 days from birth). Raw milk samples were collected from the two breeds at three points of their lactation stage given as early (42-75 days after birth), mid (76-120 days after birth) and late lactation (121 days until end of lactation). Each raw milk sample was divided into two parts (100 $\mathrm{mL}$ each), one for raw milk analysis and the other for cream collection. For cream collection, $100 \mathrm{~mL}$ of raw milk was placed in centrifuge tube formula falcons $(2 \times 50 \mathrm{~mL})$ and centrifuged for $15 \mathrm{~min}$ at $2250 \mathrm{~g}$ in a refrigerated centrifuge $\left(4^{\circ} \mathrm{C}\right)$. The cream was collected from the surface of the tube, put on a new plastic tube and frozen at $-20^{\circ} \mathrm{C}$. From $100 \mathrm{~mL}$ of milk was collected approximately $6-8 \mathrm{~g}$ of cream.

\subsection{Lipid extraction}

Total lipids of homogenised raw milk and cream samples were extracted according to a modification of the protocol of Martini et al. (2006). In detail, $20 \mathrm{~mL}$ chloroform was added to $2 \mathrm{~mL}$ of milk or to $1 \mathrm{~g}$ of cream in a tube. After vortex for $2 \mathrm{~min}$, samples were centrifuged for $15 \mathrm{~min}(3000 \mathrm{rpm})$ in $5{ }^{\circ} \mathrm{C}$. The lower phase was received and procedure was repeated. The extracted fat was concentrated to dryness using a speedvac (CentriVap Benchtop Centrifugal Vacuum Concentrator with acrylic lid and Heat Boost, Labconco, USA). The extracted lipids were weighed in order to determine 
Table 1 Composition and analysis of lactating ewes' diet

\begin{tabular}{|c|c|c|c|}
\hline Components (\%) & Basal ration & \multicolumn{2}{|l|}{ Lactation ration } \\
\hline Maize & 74.06 & \multicolumn{2}{|l|}{64.41} \\
\hline Sunflower meal & 6.99 & \multicolumn{2}{|l|}{0.00} \\
\hline Soybean meal & 2.72 & \multicolumn{2}{|l|}{24.82} \\
\hline Rice bran & 5.00 & \multicolumn{2}{|l|}{0.28} \\
\hline Calcium Phosphate & 2.52 & \multicolumn{2}{|l|}{1.66} \\
\hline Limestone & 1.80 & \multicolumn{2}{|l|}{1.63} \\
\hline Molasse & 6.00 & \multicolumn{2}{|l|}{6.00} \\
\hline Salt & 0.50 & \multicolumn{2}{|l|}{0.70} \\
\hline Vitamins \& Trace elements & $0.401^{\mathrm{a}}$ & \multicolumn{2}{|l|}{$0.502^{\mathrm{b}}$} \\
\hline Analysis & Basal ration & Lactation ration & Alfalfa hay \\
\hline Dry matter (\%) & 88.9 & 89.1 & 88.1 \\
\hline Net energy (MJ.kg $\left.{ }^{-1}\right)$ & 7.0 & 7.3 & 4.17 \\
\hline Crude protein $(\%)$ & 10.00 & 17.00 & 16.8 \\
\hline Crude fibre (\%) & 3.84 & 2.18 & 30.4 \\
\hline Ash (\%) & 6.99 & 6.68 & 9.78 \\
\hline $\mathrm{Ca}(\%)$ & 1.20 & 1.00 & - \\
\hline $\mathrm{P}(\%)$ & 0.90 & 0.70 & - \\
\hline
\end{tabular}

${ }^{\text {a } V i t a m i n s ~ a n d ~ t r a c e ~ e l e m e n t s ~ c o n t a i n e d ~ p e r ~ k i l o g r a m ~ o f ~ b a s a l ~ r a t i o n: ~} 100 \mathrm{mg} \mathrm{Mn}, 108 \mathrm{mg} \mathrm{Zn,} 90 \mathrm{mg} \mathrm{Fe}$, $4.5 \mathrm{mg}$ I, $0.2 \mathrm{mg} \mathrm{Se}, 0.675 \mathrm{mg} \mathrm{Co}, 12,600 \mathrm{KIU}$ of vitamin A, $2520 \mathrm{KIU}$ of vitamin D3 and $27 \mathrm{mg}$ of vitamin E

${ }^{\mathrm{b}}$ Vitamins and trace elements contained per kilogram of lactation ration: $130 \mathrm{mg} \mathrm{Mn}, 144 \mathrm{mg} \mathrm{Zn}, 120 \mathrm{mg} \mathrm{Fe}$, $6 \mathrm{mg} \mathrm{I}, 27 \mathrm{mg} \mathrm{Se}, 0.9 \mathrm{mg} \mathrm{Co}, 16,800 \mathrm{KIU}$ of vitamin A, $3360 \mathrm{KIU}$ of vitamin D3 and $36 \mathrm{mg}$ of vitamin E

the total lipid (TL) content, then redissolved in chloroform/methanol $(9: 1, v / v)$ and finally stored at $0{ }^{\circ} \mathrm{C}$ until further use. To prevent oxidation, t-butyl-hydroquinone was added to all samples during preparation.

\subsection{Gas chromatography analysis of fatty acid methyl esters}

Fatty acid methyl esters (FAMEs) of total lipids (TLs) were prepared according to the procedure described by Sinanoglou et al. (2013). Quantitative and qualitative analyses were performed on an Agilent 6890 Series Gas Chromatograph (Agilent Technologies, Palo Alto, CA, USA) equipped with a flame ionisation detector, as described by Sinanoglou et al. (2013). DB-23 capillary column $(60 \mathrm{~m} \times 0.25 \mathrm{~mm}$ i.d. $0.15-\mu \mathrm{m}$ film $)$ (Agilent Technologies, Palo Alto, CA, USA) was used. The identification and the relative content of fatty acids in each sample were determined according to the procedure described by Sinanoglou et al. (2013).

\subsection{Lipid quality indices calculations}

The ratio between hypocholesterolaemic and hypercholesterolaemic fatty acids $(\mathrm{h} / \mathrm{H})$ was calculated according to the formula suggested by Santos-Silva et al. (2002): 


$$
\begin{aligned}
\mathrm{h} / \mathrm{H}= & (\mathrm{C} 18: 1 \omega 9+\mathrm{C} 18: 2 \omega 6+\mathrm{C} 20: 4 \omega 6+\mathrm{C} 18: 3 \omega 3+\mathrm{C} 20: 5 \omega 3+\mathrm{C} 22: 5 \omega 3+\mathrm{C} 22: 6 \omega 3) \\
& /(\mathrm{C} 14: 0+\mathrm{C} 16: 0) .
\end{aligned}
$$

The peroxidisability index (PI) was calculated according to the formula proposed by Erickson (1992):

$\mathrm{PI}=(0.025 \cdot$ monoenes $)+(1 \cdot$ dienes $)+(2 \cdot$ trienes $)+(4 \cdot$ tetraenes $)+(6 \cdot$ pentaenes $)+(8 \cdot$ hexaenes $)$.

The atherogenic index (AI) and thrombogenic index (TI) were calculated according to the formulas proposed by Ulbrich and Southgate (1991):

$$
\mathrm{AI}=[12: 0+(4 \times 14: 0)+16: 0] /(\omega-3 \mathrm{PUFA}+\omega-6 \mathrm{PUFA}+\mathrm{MUFA})
$$

and

$$
\mathrm{TI}=(14: 0+16: 0+18: 0) /(0.5 \mathrm{MUFA}+0.5 \omega-6 \mathrm{PUFA}+3 \omega-3 \mathrm{PUFA}+\omega-3 \mathrm{PUFA} / \omega-6 \mathrm{PUFA}) .
$$

\subsection{Statistical analysis}

Measurements were obtained in triplicate and averaged values of fatty acids were calculated. The variables for C4:0, C6:0, C8:0, C10:0, C10:1, C12:0, C14:0, iso C15:0, C15:0, C16:0, C18:0, C18:1 $\omega-9, \mathrm{C} 18: 2$ cis-9trans-11, C18:2 $\omega-6$ and C20:0 fatty acids; the sums of saturated fatty acid (SFA), monounsaturated fatty acid (MUFA), PUFA, UFA, $\omega-6$ and $\omega-3$; and the ratios $\omega-6 / \omega-3$, MUFA/SFA and PUFA/SFA, as well as the lipid quality indices $\mathrm{h} / \mathrm{H}, \mathrm{AI}$, TI and PI, were treated as dependent variables and analysed using a two-way analysis of variance including as fixed factors in the model the stage of lactation, the breed and their interaction. The fixed effect of stage of lactation had three levels (early, 45-75 days after weaning; mid, 76-120 days after weaning; and late, 121 days until the end of milking). The fixed effect of breed had two levels (Karagouniko and Chios). The values for the remaining variables as C13:0, $\mathrm{C} 14: 1$, anteisoC15:0, C15:1, isoC16:0, C16:1, isoC17:0, anteisoC17:0, cycloC17:0,

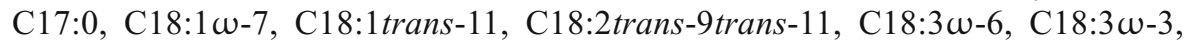

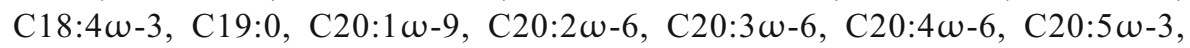
$\mathrm{C} 22: 1 \omega-9, \mathrm{C} 22: 4 \omega-6, \mathrm{C} 22: 5 \omega-6, \mathrm{C} 24: 0$ and $\mathrm{C} 22: 6 \omega-3$ fatty acids did not meet the ANOVA assumptions (i.e. normal distribution and homogeneity of variances within fixed factor classes), and for this reason, the Mann-Whitney $U$ or the Kruskal-Wallis non-parametric tests were performed for each fixed factor. The Bonferroni test was used for pairwise and multiple comparisons. Possibilities less than 0.05 were considered as statistically significant $(P<0.05)$. All statistical calculations were performed with the SPSS package (IBM SPSS Statistics, version 19.0, Chicago, IL, USA) statistical software for Windows.

Discrimination analysis was based on the probabilistic neural network (PNN) classifier (Specht 1990) and the leave-one-out (LOO) cross-validation method (Theodoridis and Koutroumbas 2008). In each class comparison (e.g. Karagouniko vs Chios), fatty acids and LQI values were combined, following the exhaustive search method, in all possible ways (i.e. 2, 3, etc.) in the design of the PNN, and at each combination, the PPN classification accuracy was examined, retaining at the end the design that produced the highest classification accuracy with the least number of features. The maximum number of allowable feature combinations in each design was limited to one third of the members of the smallest class in order to avoid 
overfitting and, thus, overestimation of the design accuracy (Theodoridis and Koutroumbas 2008). Discriminant analysis was performed using Matlab software (Matlab version 6.04, The MathWorks, Inc., Natick, MA, USA).

\section{Results and discussion}

\subsection{Fatty acid profile and lipid quality indices of raw milk and cream}

Gas chromatography (GC-FID) analysis of the lipid samples revealed the presence of 42 fatty acids (FAs). Fatty acid proportions, sums and ratios and LQI values for raw milk samples are presented in Tables 2 and 3. The relative variables for cream samples are presented in Tables 4 and 5.

Fatty acid sums in all samples decreased in the order of SFA $>$ MUFA $>$ PUFA which is in agreement with the findings of other studies (Signorelli et al. 2008). More than $70 \%$ of raw milk and cream total fatty acids comprised saturated fatty acids (SFAs) from C4:0 (butyric acid) to C18:0 (stearic acid). Palmitic acid (C16:0), the major saturated fatty acid (SFA), constantly accounted for more than $19 \%$ of total fatty acids. The relatively high content of lauric acid (C12:0) (Tables 2 and 4), which has atherogenic effect in human diet, could be compensated by its multiple roles as an antibacterial and antiviral agent (Batovska et al. 2009). An interesting feature, concerning raw milk fat (Tables 2 and 3) and cream fat (Tables 4 and 5), was the identification of odd-, branched- and cyclo-chain saturated fatty acids such as the isomers of pentadecanoic acid (C15:0, isoC15:0 and anteisoC15:0), of hexadecanoic acid (isoC16:0) and of heptadecanoic acid (C17:0, isoC17:0, anteisoC17:0 and cycloC17:0). Vlaeminck et al. (2006) reported that odd- and branched-chain fatty acids in milk fat are largely derived from bacteria leaving the rumen. These fatty acids can be found in animal tissues, especially those of ruminants, and their content can often be used as a taxonomic marker (Hopkins and Macfarlane 2000).

Concerning the unsaturated fatty acids (UFAs), substantial proportions of oleic $(\mathrm{C} 18: 1 \omega-9)$ and linoleic $(\mathrm{C} 18: 2 \omega-6)$ acids were identified in raw milk and cream total lipids. It is important to point out the identification of the C18:1trans-11 (vaccenic acid, VA) as well as of the conjugated linoleic acid (CLA) isomers, C18:2cis-9trans-11 (rumenic acid) and C18:2trans-9trans-11. It is reported that sheep mammary glands are capable of synthesising CLA from VA (Moioli et al. 2012). Both vaccenic and rumenic acids, which are reported to have anticarcinogenic and antiatherogenic properties (Bhattacharya et al. 2006), were found at sufficient levels in all milk fat samples. Among the $\omega-3$ PUFA, the main fatty acids identified were steriadonic $(\mathrm{C} 18: 4 \omega-3)(\geq 0.48 \%)$ and

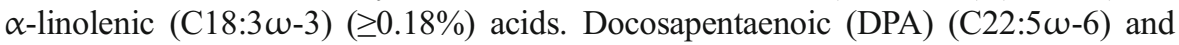
docosahexaenoic (DHA) (C22:6w-3) acids were also detected in minor proportions.

The $\omega-6 / \omega-3$ ratio, which is an important determinant for reducing the risk of many chronic diseases (Simopoulos 2008), is beneficial, as their values were lower to the recommended value of 4:1 in all raw milk and cream total lipid samples (Tables 2 and 4). The hypocholesterolaemic/hypercholesterolaemic $(\mathrm{h} / \mathrm{H})$ ratio ranged from 0.50 to 0.69 in all examined samples, indicating that raw milk and cream fat have low cholesterolaemic effect. Peroxidisability index (PI) ranged from 8.45 to 14.29 in all examined samples, reflecting the relative rate of lipid peroxidation. Furthermore, 


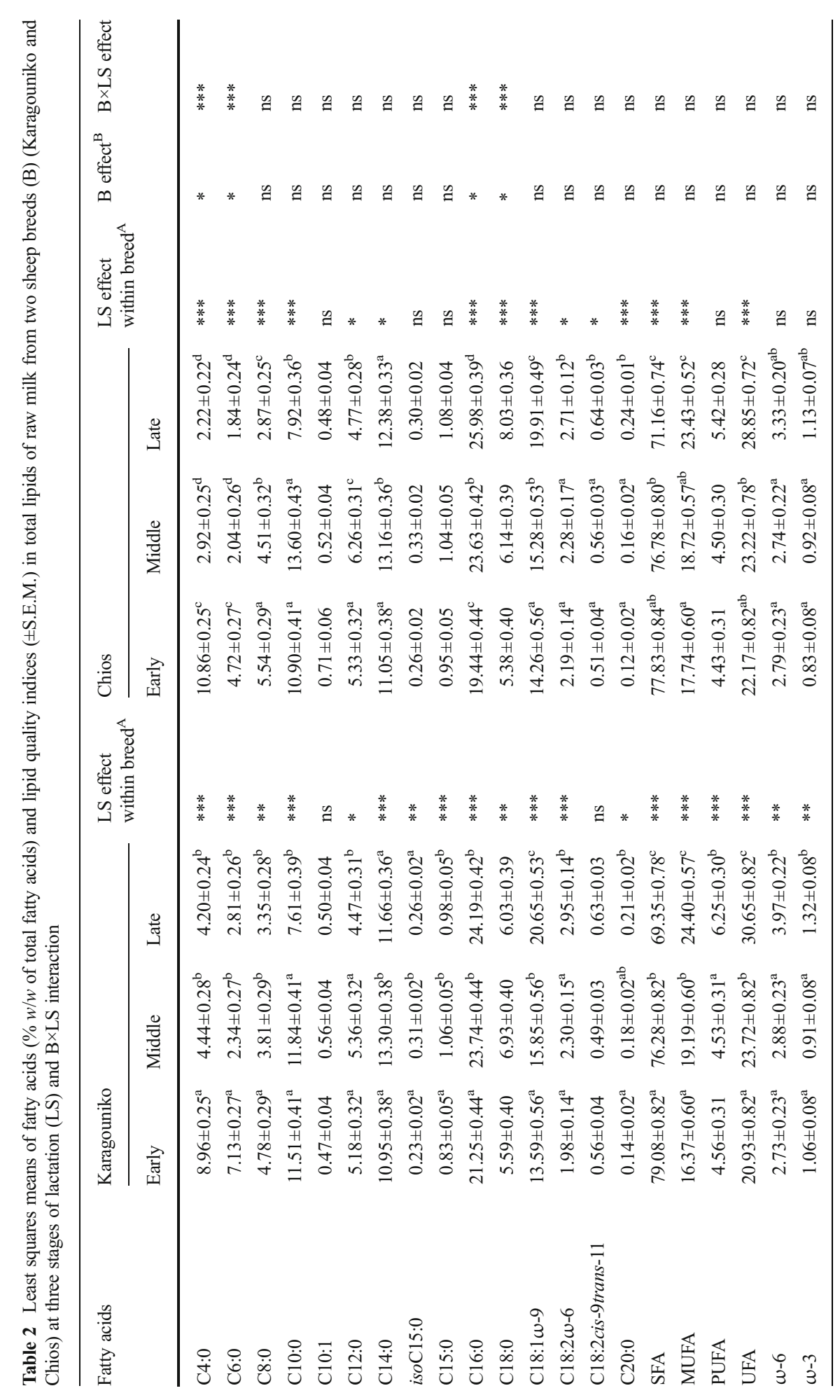




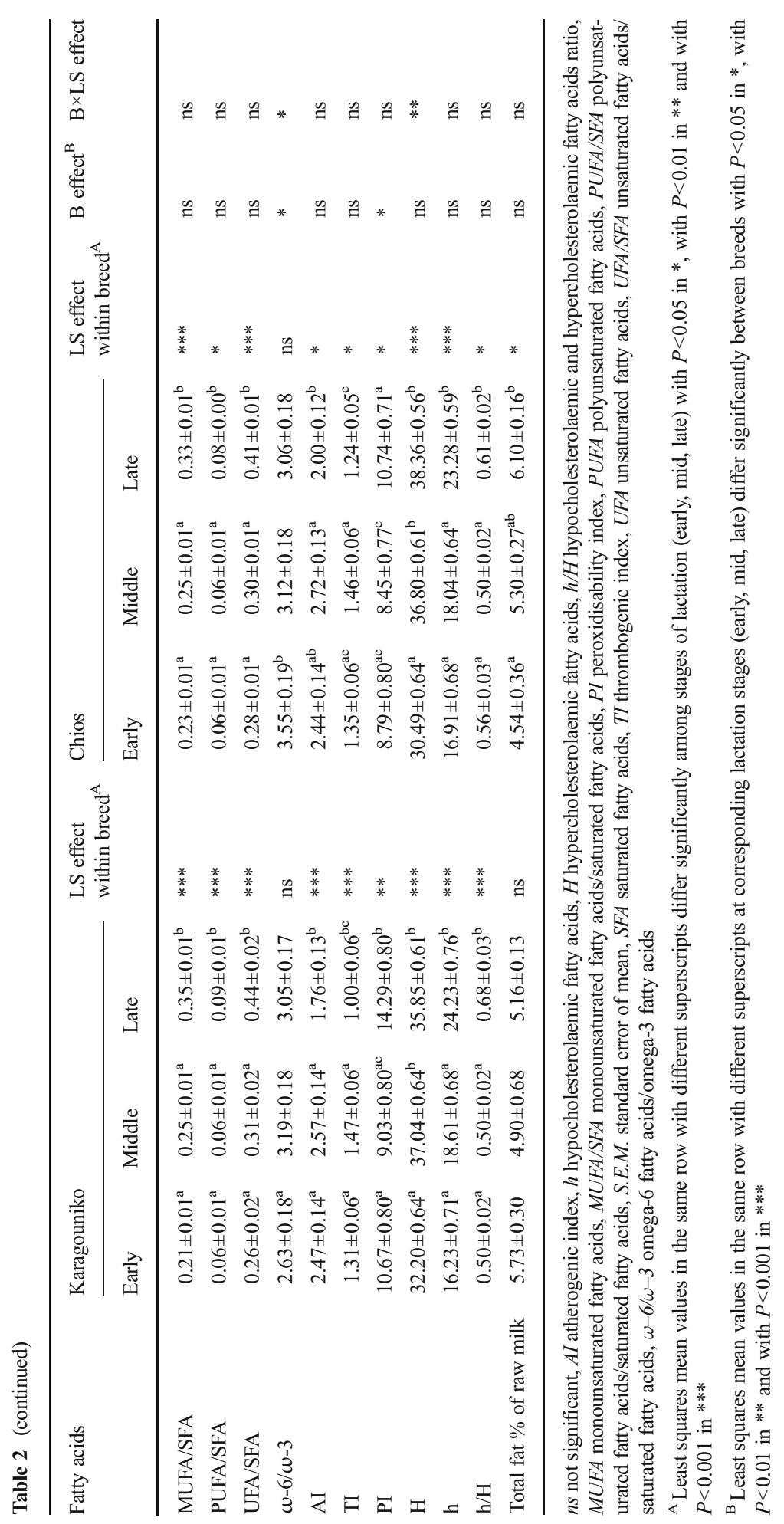




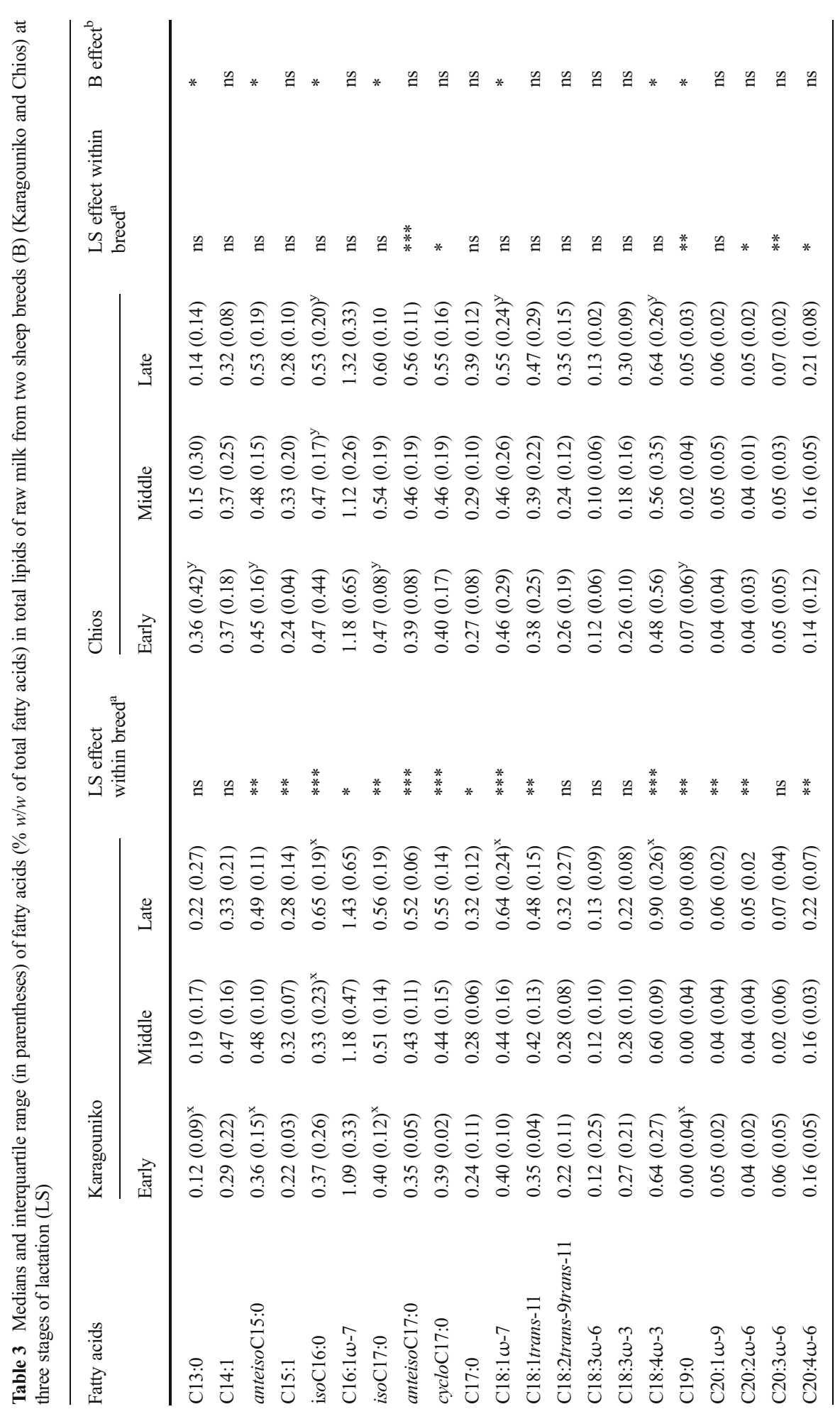




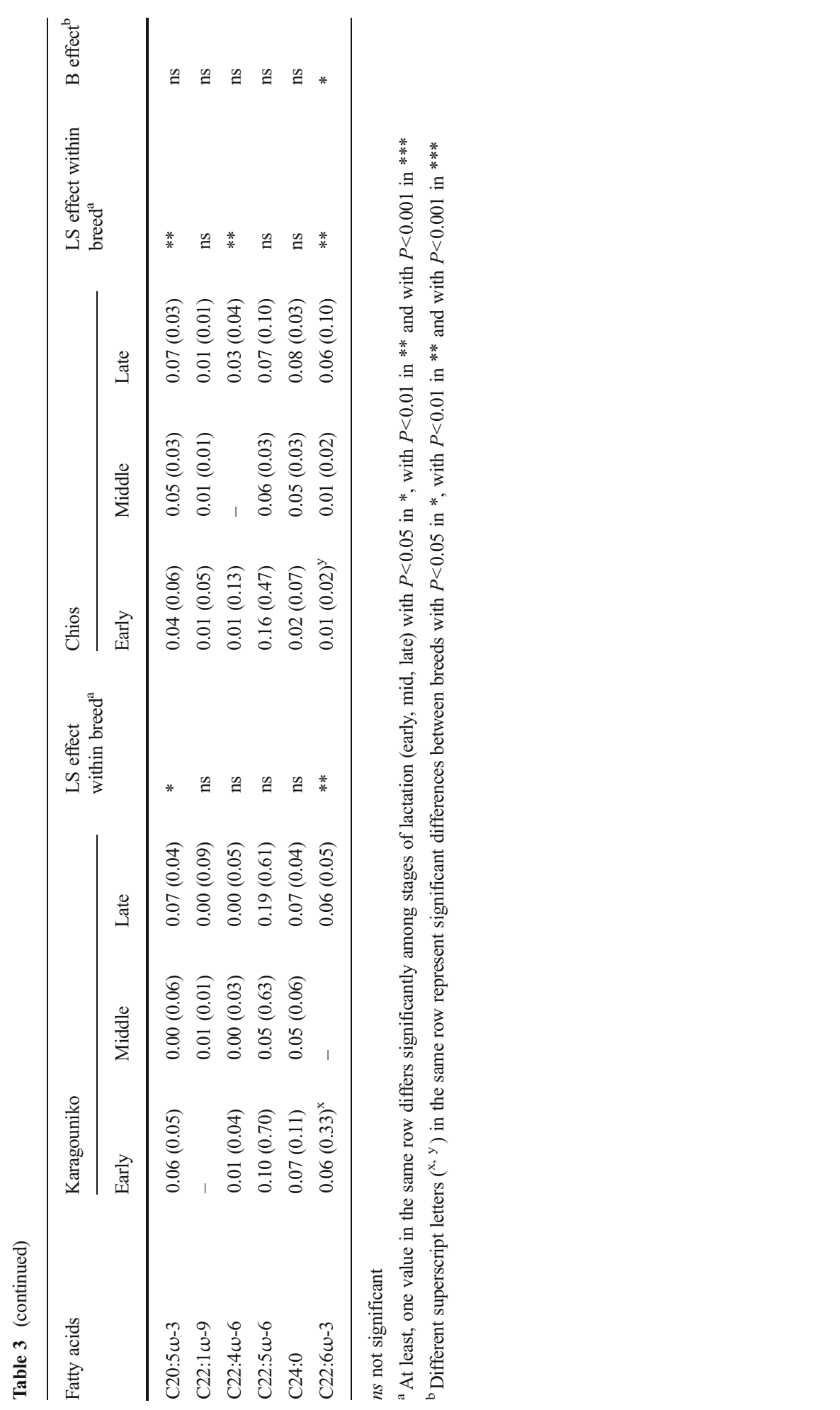

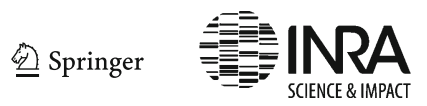




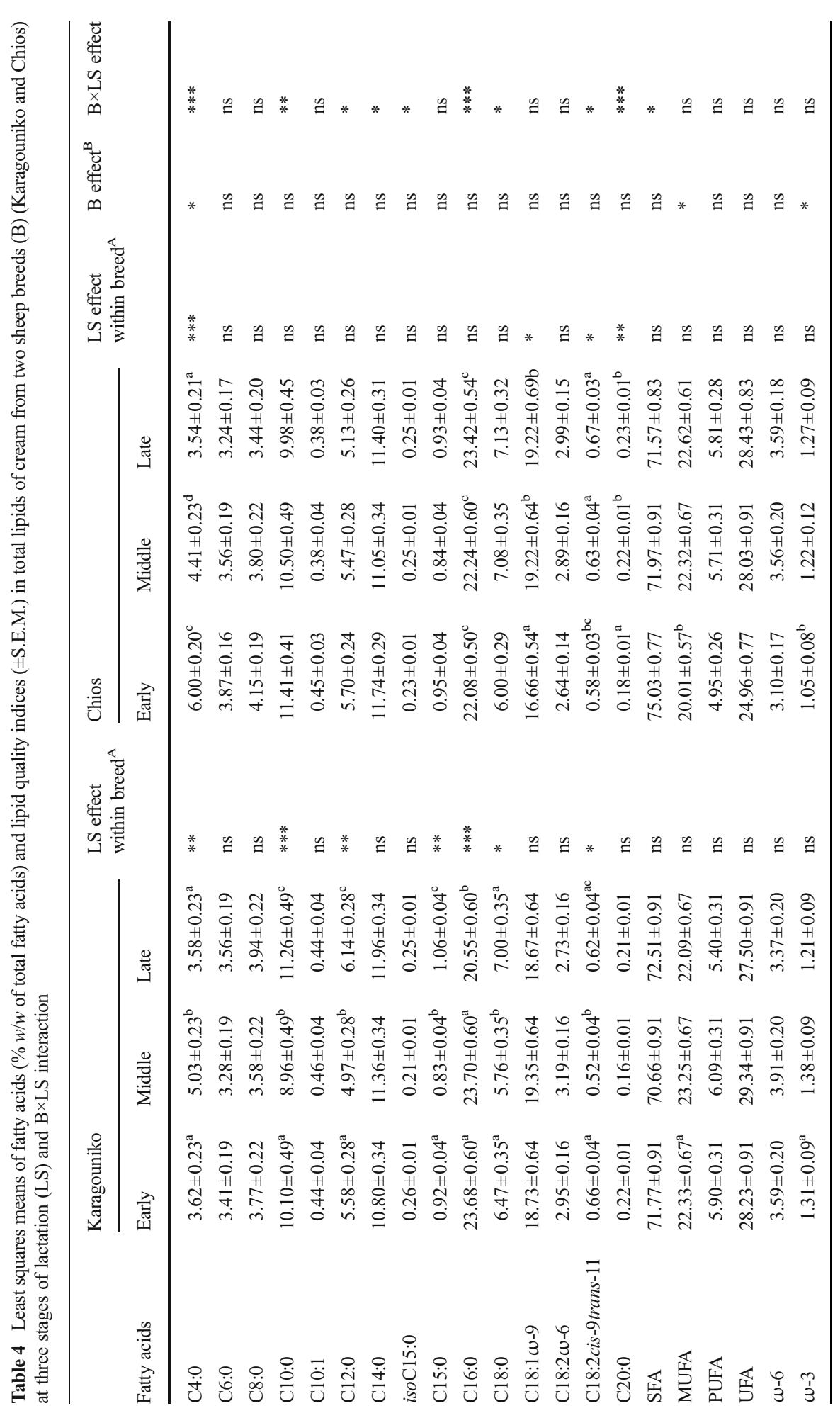




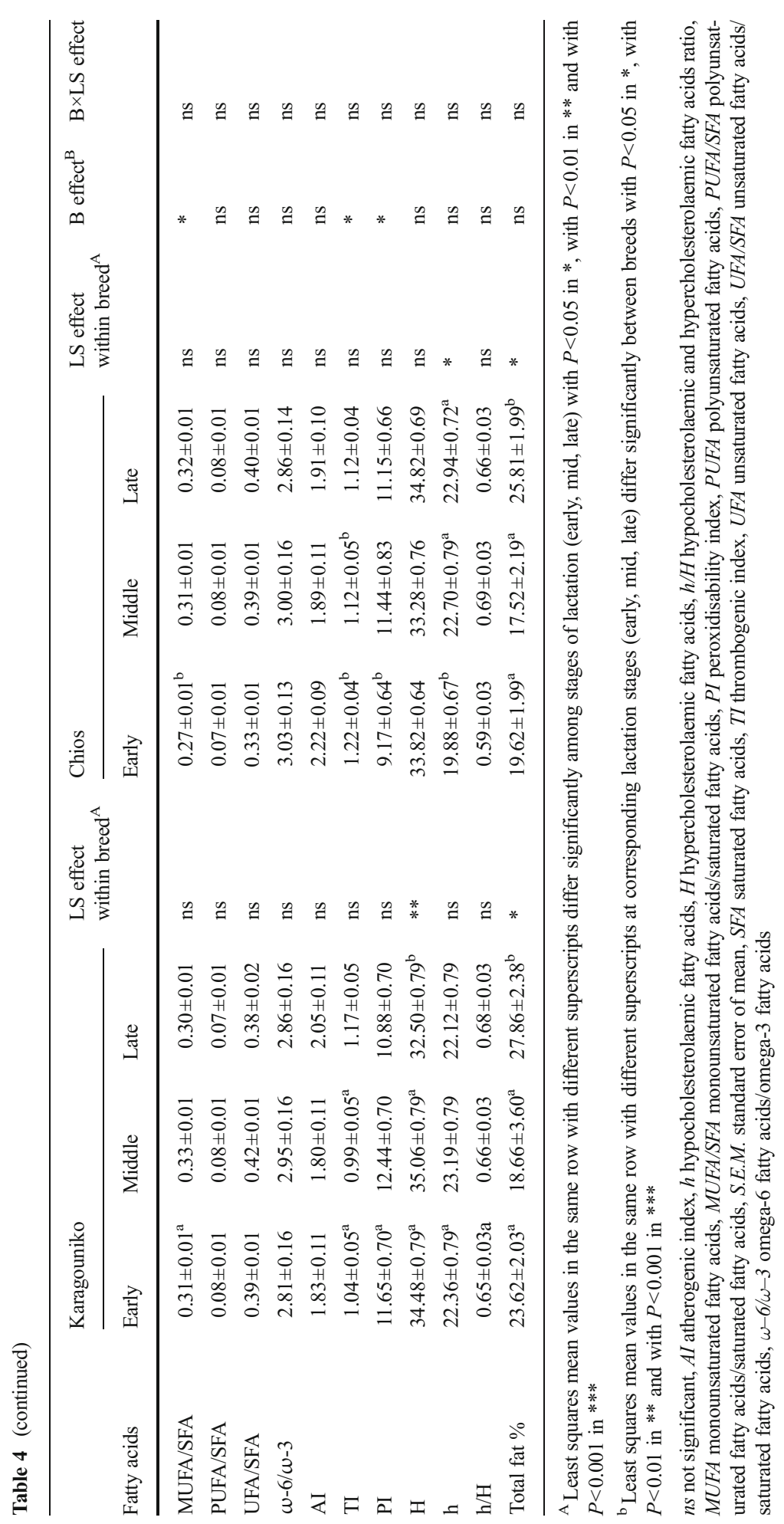




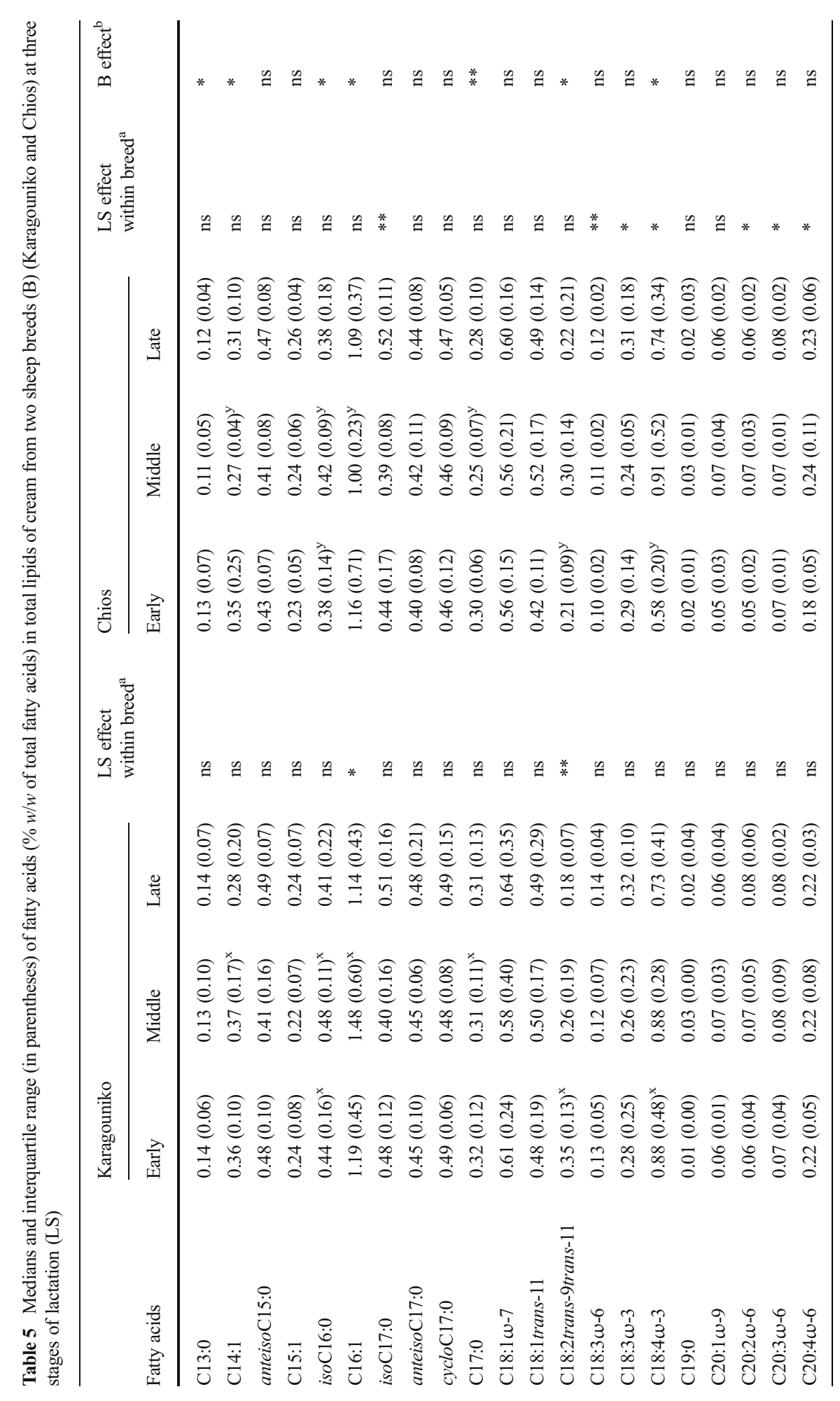




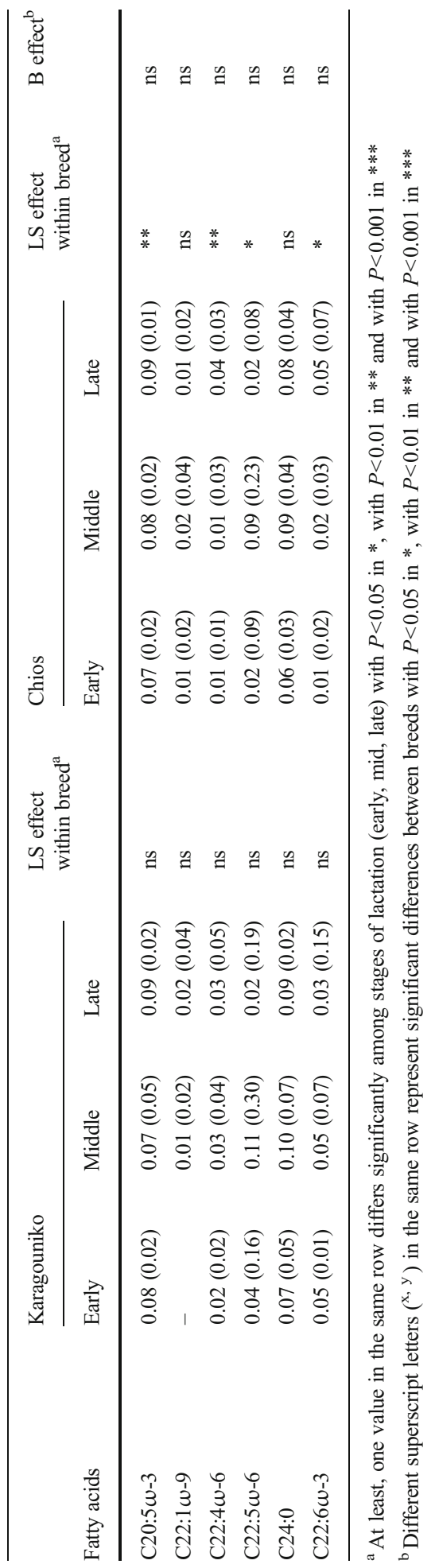


atherogenic index $(\mathrm{AI})$ showed significantly $(P<0.05)$ higher values than the thrombogenic index (TI) in raw milk and cream fat (Tables 2 and 4). Therefore, atherogenic index values of sheep raw milk fat were found to be almost half of those reported by Nantapo et al. (2014) for cow milk fat, similar to those reported by Soják et al. (2013) for ewe milk fat and lower to those reported by Mierlita et al. (2011) for Spanca ewe milk fat.

The most interesting features in raw milk and cream fat, according to the above data, were the high proportions of short- and medium-chain fatty acids (SCFA and MCFA), as well as the existence of CLA isomers and PUFA even at low proportions. Short- and medium-chain fatty acids are reported to have important nutritional and therapeutic significance (Nagao and Yanagita 2010), as well as technological impact in flavour and aroma of milk products (Slačanac et al. 2010). Bhattacharya et al. (2006) reported that CLA isomers may have numerous health effects, but there is very limited literature on human studies, and it is difficult to clearly establish the protective role of CLA isomers in human health. Furthermore, PUFA decreases LDL cholesterol concentration and the total/high-density lipoprotein (HDL) cholesterol ratio (FAO/WHO 2008).

\subsection{Effect of breed on fatty acid profile and LQI of raw milk and cream fat}

Information related to the breed effect in raw milk and cream FA composition and LQI values could be a prelude for the increased use of these indigenous sheep breeds for milk production.

Multivariate analysis in relation to the between-breed differentiation in raw milk fat samples highlighted the short-chain butyric (C4:0) and caproic (C6:0) acids as important $(P<0.05)$ (Table 2). At early lactation stage, Karagouniko ewes in contrast to Chios ewes produced more C6:0 and less C4:0. An opposite trend was observed at mid and late lactation as Karagouniko ewes produced more C4:0 compared to Chios ewes. Moving to the cream fat samples (Table 4), the same differences between breeds were observed concerning C4:0.

For the subset of fatty acids which deviated from normality, few differences between breeds were revealed within the same stage of lactation for both raw milk and cream samples (Tables 3 and 5).

Concerning the fatty acid ratios and LQI values, the findings are in the same direction for both raw milk and cream samples (Tables 2 and 4). Karagouniko breed raw milk provided lower $\omega-6 / \omega-3$ ratio and higher PI values than Chios breed $(P<0.05)$. Advantageously, Karagouniko breed cream provided higher MUFA and $\omega-3$ FA proportion and PI values and lower TI values than Chios breed $(P<0.05)$. The above results indicate quantitative variability concerning fatty acid proportions, ratios and LQI values between the two studied indigenous Greek sheep breeds. Raw milk and cream fat from Karagouniko breed had a healthier fatty acid profile than those from Chios breed, since Karagouniko was characterised by higher $\omega-3$ proportion and lower $\omega-6 / \omega-3$ ratio and TI values.

Scatter diagrams (Fig. 1a, b) showed that Karagouniko raw milk samples were well separated from Chios ones, whereas cream samples were grouped according to the breed with a significant overlapping, which suggests similarity among samples. Figure 1a shows an adequate separation of Karagouniko and Chios breed raw milk samples with $93.85 \%$ overall discrimination accuracy, via $\mathrm{C} 4: 0$ and C6:0 fatty acids 
a

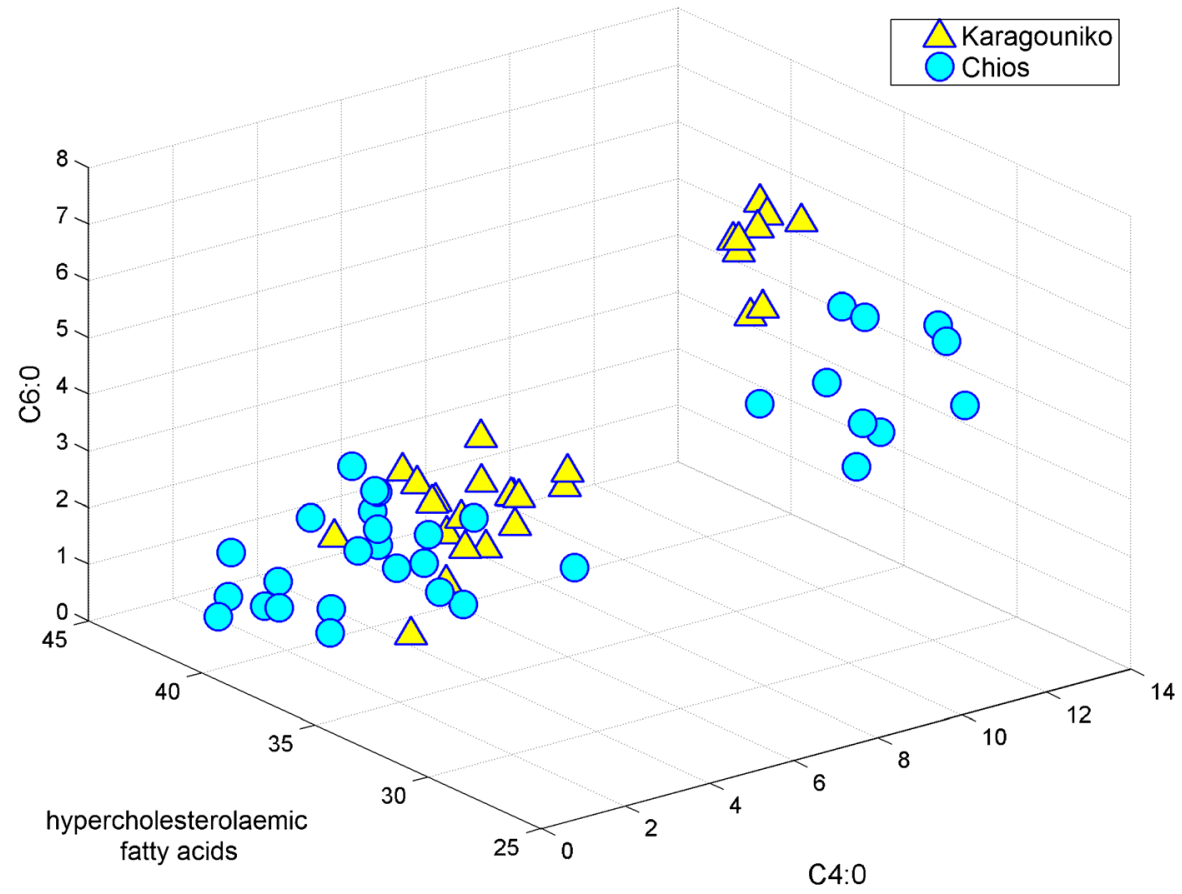

b

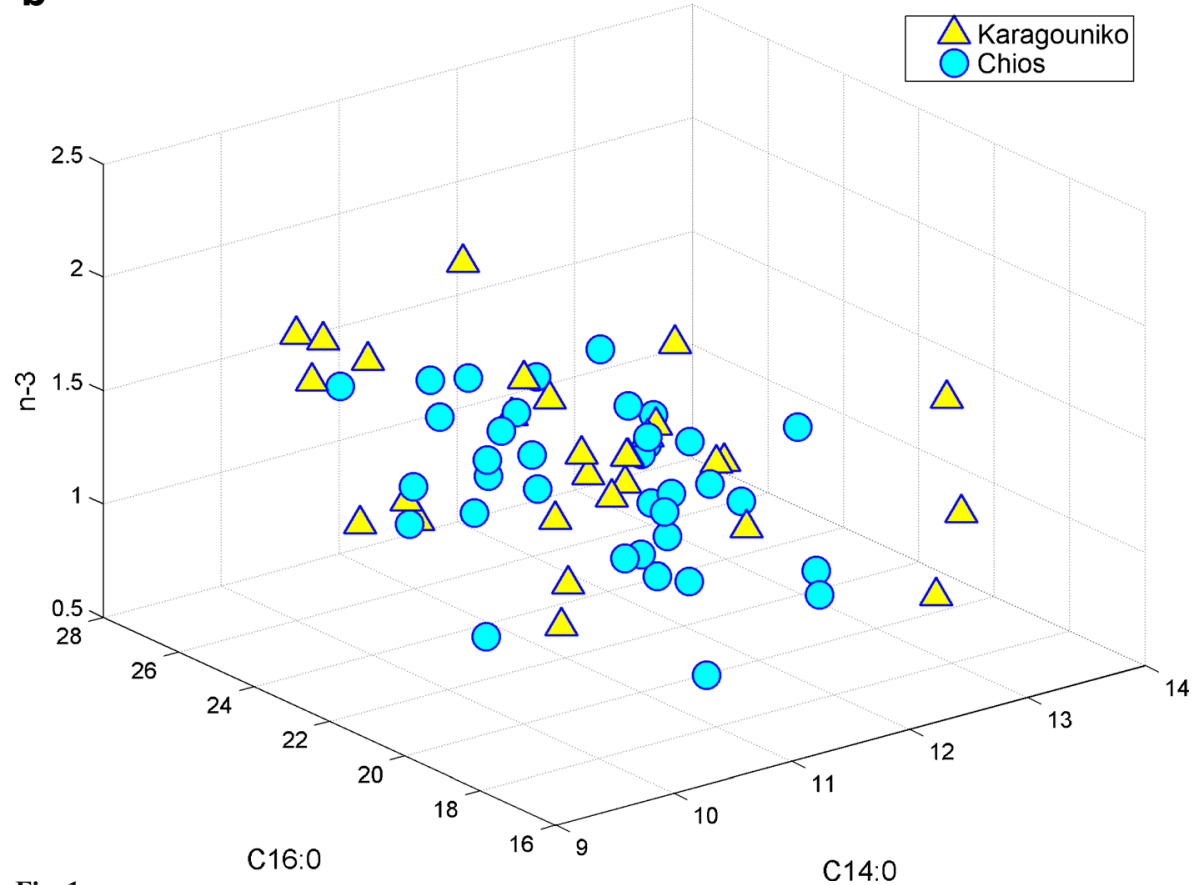

Raw milk, 3 lactation stages, accuracy:93.8462\%

$\triangle$ Karagouniko

$\triangle 908$

C4:0
000

Butter milk, 3 lactation stages, accuracy: $75.7576 \%$

Fig. 1

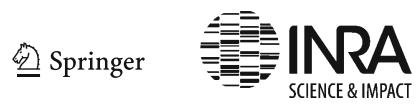


Fig. 1 Scatter diagrams of Karagouniko and Chios a raw milk total lipid samples using 3D features (C4:0 and C6:0 fatty acids and $\mathrm{H}$ index) and $\mathbf{b}$ cream total lipid samples utilising 3D features (C14:0, C16:0 and $\omega-3$ fatty acids)

and $\mathrm{H}$ index. Moreover, Fig. $1 \mathrm{~b}$ shows the separation of Karagouniko and Chios breed cream samples with $75.76 \%$ overall precision, via C14:0, C16:0 and $\omega-3$ fatty acids. These findings demonstrate that the fatty acid profile and LQI of milk fat may become suitable criteria for breed selection. In accordance with Signorelli et al.'s (2008) findings, FA profile could be proposed as an indicator of breed type. In the same sense, Mierlita et al. (2011) reported that breed markedly affects the FA profile of ewe milk fat.

\subsection{Effect of lactation stage on fatty acid profile and on LQI of raw milk and cream fat}

Under normal conditions, a mixture of raw milk, irrespective of the lactation stage, is used for the production of dairy products. To this extent, it would be interesting to determine the most appropriate lactation period, if any, for milk collection and for the manufacture of dairy products with health benefits.

\subsubsection{Effect of lactation stage on fatty acid profile and on LQI of raw milk fat}

The individual FA proportions, sums and ratios as well as the LQI values of raw milk fat, at the three lactation stages, are shown in Tables 2 and 3.

The sum of short-chain FA (C4:0-C6:0) in Karagouniko and Chios breed raw milk fat showed a significant decrease as lactation progressed, diminishing from 16.09 to $15.58 \%$ at early lactation to 7.01 and $4.06 \%$ at late lactation, respectively (data calculated from Table 2). The interactions of the breed and the lactation stage in relation to the above results confirm higher short-chain FA proportions at early lactation than at mid and late lactation. Similarly, the sum of medium-chain FA (C8:0-C13:0) showed a significant $(P<0.05)$ decrease, diminishing from 21.62 to $22.2 \%$ at early lactation to 15.7 and $15.76 \%$ at late lactation, respectively (data calculated from Tables 2 and 3). These results are in agreement with those reported by Strzałkowska et al. (2009) for goat milk fat and by Nantapo et al. (2014) for cow milk fat. Myristic acid $(\mathrm{C} 14: 0)$ proportion showed the highest $(P<0.001)$ increase at mid lactation, and palmitic acid $(\mathrm{C} 16: 0)$ at late lactation $(P<0.001)$, whereas lauric acid $(\mathrm{C} 12: 0)$ proportion showed the highest $(P<0.05)$ decrease at late lactation. Furthermore, stearic acid $(\mathrm{C} 18: 0)$ had higher $(P<0.01)$ proportion at mid than at early and late lactation for the Karagouniko breed. For the Chios breed, stearic acid proportion showed the highest $(P<0.001)$ increase at late lactation. According to the above results, the total SFAs were reduced significantly $(P<0.001)$ during late lactation, while the long-chain SFA (C14:0-C18:0) increased. Chilliard et al. (2003) reported that there is a decrease in the medium-chain FA percentage in milk fat, if long-chain FAs are available from the diet or from body fat mobilisation.

Among MUFA, a significant $(P<0.001)$ increase was observed in oleic $(\mathrm{C} 18: 1 \omega-9)$ acid proportion, during late lactation for both breed milk samples (Table 2), which is in accordance with Strzałkowska et al.'s (2009) findings. Furthermore, C16:1 $\omega-7$ and 

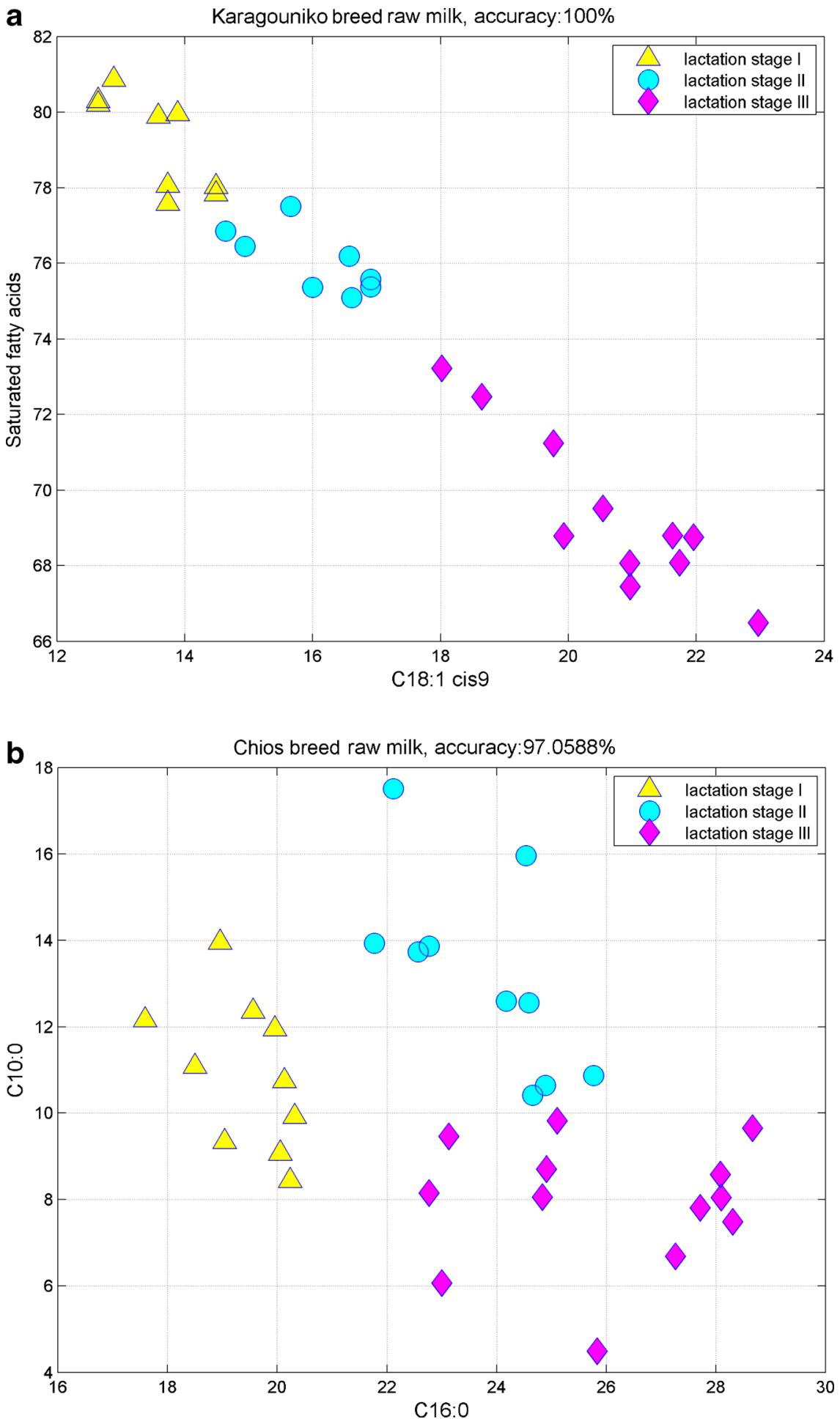

Fig. 2 Scatter diagrams of a Karagouniko and $\mathbf{b}$ Chios raw milk total lipid samples, using two features during lactation

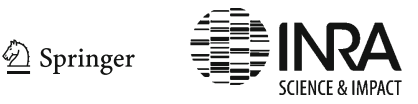




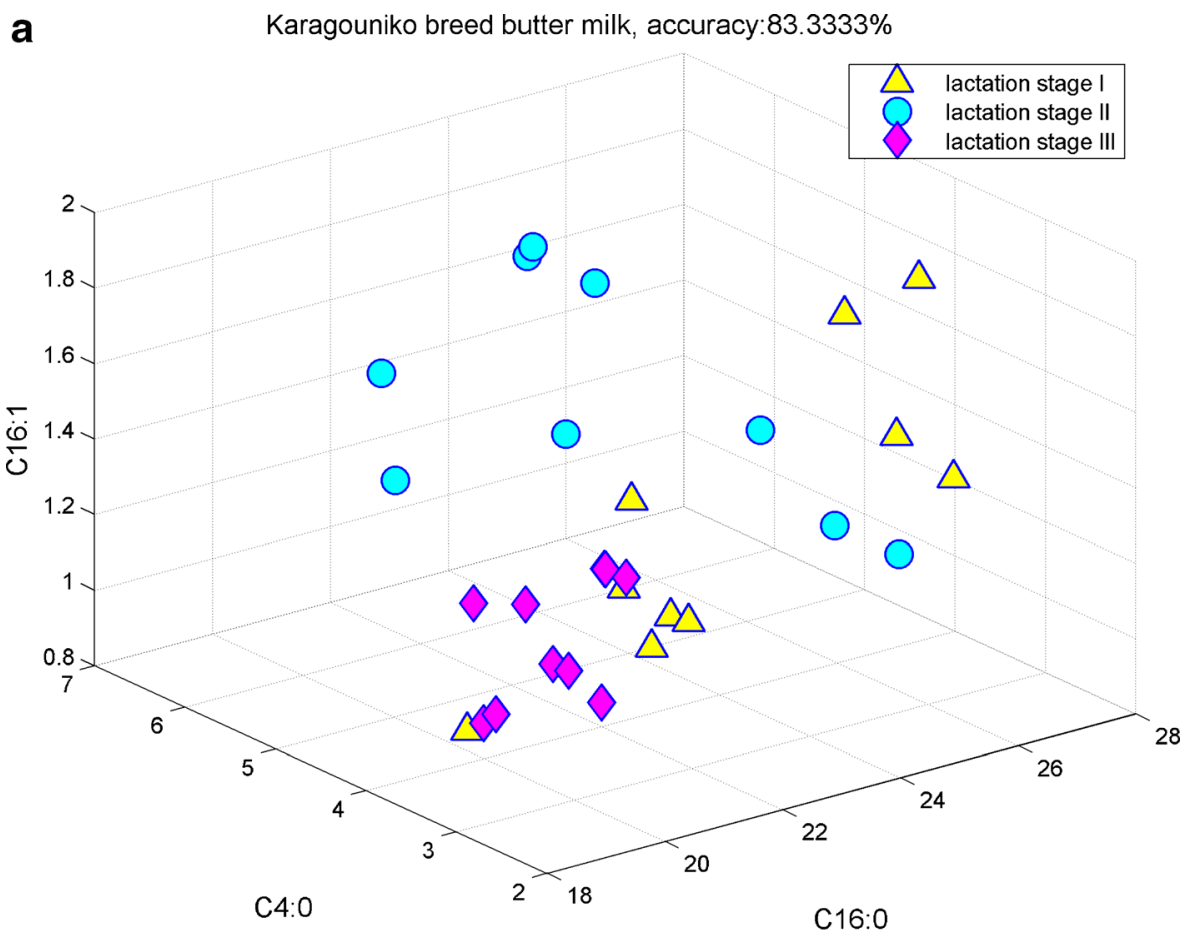

b

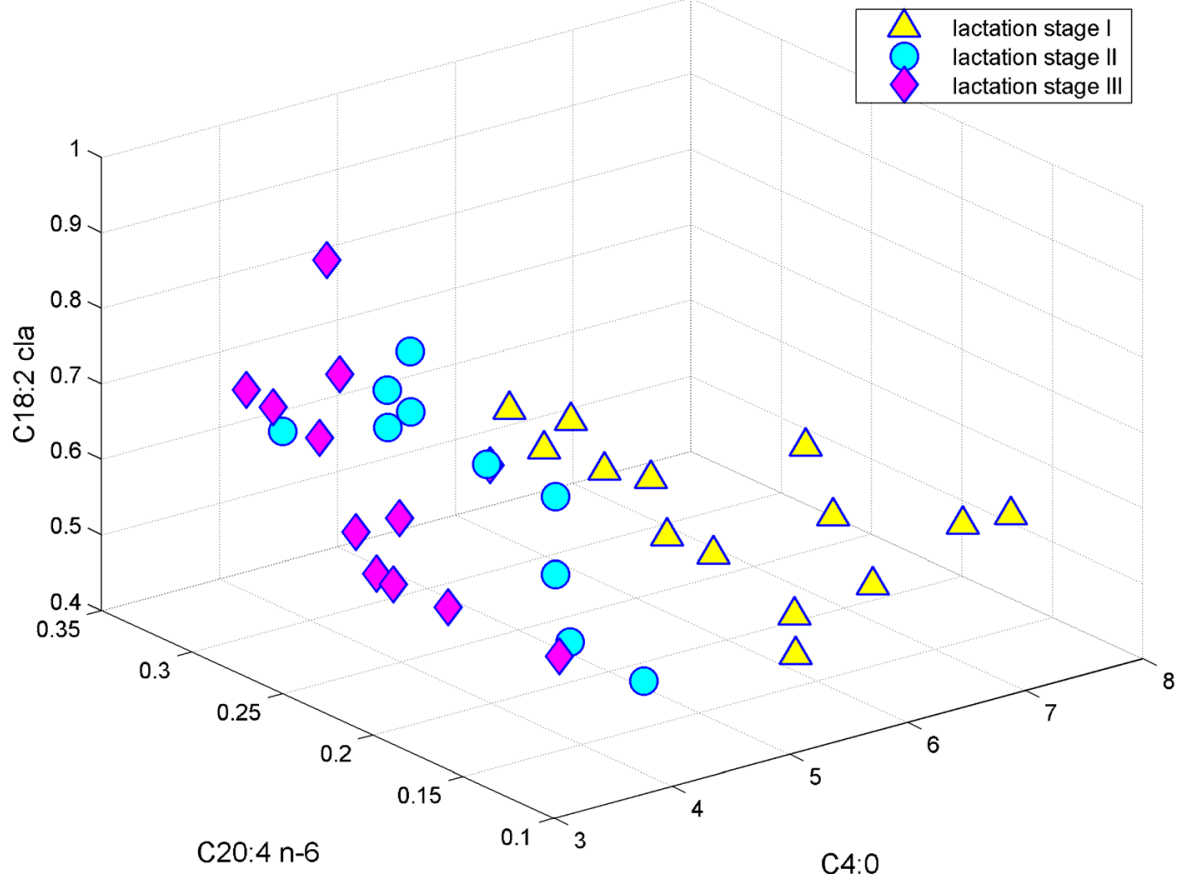

Fig. 3 Scatter diagrams of a Karagouniko and $\mathbf{b}$ Chios cream total lipid samples, using three features during lactation 
C18:1 $\omega-7$ FA proportions increased significantly during late lactation, only for the Karagouniko breed (Table 3).

Concerning PUFA, a significant increase in C18:2w-6, C20:2w-6, C20:4w-6 and C20:5 $\omega-3$ FA proportions was observed for both breed milk samples (Tables 2 and 3).

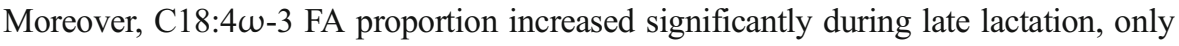
for the Karagouniko breed (Table 3). CLA isomer C18:2cis-9trans-11 proportion increased significantly $(P<0.05)$ during late lactation only for the Chios breed unlike Tsiplakou et al.'s (2006) findings, whereas C18:2trans-9trans-11 proportion showed no significant variation throughout lactation.

Generally, MUFA and UFA as well as MUFA/SFA, PUFA/SFA and UFA/SFA ratios were highest $(P<0.05)$ in late lactation for both breeds, whereas SFAs were lowest $(P<0.001)$ (Table 2), which is in accordance to De La Fuente et al.'s (2009) findings. Furthermore, MUFA and UFA increases were significant in distinguishing raw milk samples of late lactation from early and mid lactation stages. This could be perceived as an interesting result, as there is convincing evidence that replacing SFA with MUFA reduces LDL cholesterol concentration and total/HDL cholesterol (FAO/WHO 2008). The $\omega-6 / \omega-3$ ratio varied insignificantly during lactation remaining lower to the recommended value of 4:1 in all raw milk fat samples (Table 2).

Concerning late lactation, atherogenic and thrombogenic indices (AI and TI) of raw milk fat were lower $(P<0.05)$, whereas hypocholesterolaemic and peroxidisability indices ( $\mathrm{hI}$ and PI) were higher $(P<0.05)$, as compared to other lactation stages. These changes are particularly interesting, because the AI and TI decrease could reduce the potential risk of coronary heart disease (Naydenova et al. 2014).

Considering all the above results, some notable conclusions could emerge. Variations in fatty acid proportion and LQI values during lactation followed similar trends between Karagouniko and Chios breeds. The lower values observed in atherogenic and thrombogenic indices as well as the higher UFA/SFA and hypocholesterolaemic/ hypercholesterolaemic $(\mathrm{h} / \mathrm{H})$ fatty acid ratios found in raw milks from late lactation (Table 2) indicate that these raw milks may have beneficial effects on human health.

Discriminant analysis (Fig. 2a, b) enables the isolation of features that may differentiate raw milk samples according to the lactation stage. For Karagouniko breed, SFA and C18:1 $\omega-9$ managed to separate the three lactation periods with $100 \%$ overall classification accuracy, and for Chios breed, C10:0 and C16:0 fatty acids achieved $97.06 \%$ overall classification accuracy. In Karagouniko raw milk fat (Fig. 2a), C18:1 $\omega$ 9 was found to increase during lactation while SFA decreased, which is a potentially beneficial change in milk fat composition. Additionally, as shown in the scatter diagram of Fig. 2b, lactation stages were distinctly separated in Chios breed raw milk samples. This is of value, since it shows that early lactation period is characterised by the lowest C16:0 percentages, which is advantageous in cardiovascular health (FAO/WHO 2008).

\subsubsection{Effect of lactation stage on fatty acid profile and on LQI of cream fat}

The FA profiles, their sums and LQI values of cream fat are shown in Tables 4 and 5. Lactation stage did not particularly affect the fat content, the fatty acid profile and the values of lipid quality indices of cream fat, unlike the raw milk results.

Concerning short-chain SFA, the level of butyric acid (C4:0) in cream fat was higher $(P<0.01)$ in early lactation for the Chios breed and in mid-lactation for the 
Karagouniko breed. Moreover, there was a significant decrease in palmitic acid (C16:0) and a significant increase in C10:0, C12:0, C15:0 and C18:0 FA percentages in late lactation, only for Karagouniko cream fat. Furthermore, especially for Chios cream fat,

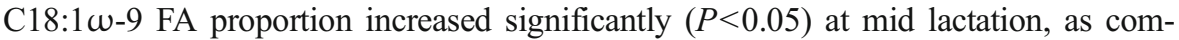
pared to early lactation stage. Concerning CLA isomers, C18:2cis-9trans-11 proportion varied significantly $(P<0.05)$ during lactation in an opposite trend for Karagouniko and Chios cream fat. Finally, HI was lowest $(P<0.05)$ during late lactation, only for Karagouniko cream fat, whereas hI decreased $(P<0.05)$ during mid lactation only for Chios cream fat. All the other fatty acid sums, ratios and indices showed only fluctuations mostly insignificant. Regarding FA with deviations from normality, a considerable number of FA proportions revealed significant differences only for Chios breed (Table 5).

Discriminant analysis (Fig. 3) attempted to classify cream samples of each breed according to the lactation stage. Karagouniko breed cream samples showed a significant overlapping, which suggests a similarity among samples irrelevant of the lactation stage (Fig. 3a). On the contrary, Chios breed cream samples showed sufficient separation of the early lactation stage from the rest with $86.11 \%$ overall classification

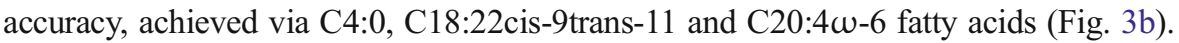
The high C4:0 proportion at early lactation is an important outcome as butyric acid is a potent inhibitor of cancer cell proliferation (Gün and Simsek 2011).

\section{Conclusions}

This study assessed the fatty acid profile and estimated the lipid quality indices of raw milk and cream fat from two indigenous Greek sheep breeds at different lactation stages. Sheep raw milk and cream fat were found to contain high proportions of shortand medium-chain fatty acids, which are of value for a healthy diet. Raw milk fatty acid profile was influenced to a higher extent by the lactation stage than by the breed factor. The relative proportions of most short- and medium-chain FA decreased as lactation progressed, whereas UFA proportion increased. Palmitic and oleic acids showed their highest proportion during late lactation. Atherogenic and thrombogenic indices decreased; on the other hand, the hypocholesterolaemic/hypercholesterolaemic $(\mathrm{h} / \mathrm{H})$ fatty acid ratio increased at late lactation. Butyric acid showed high potential for the discrimination of Karagouniko and Chios breed raw milk and cream samples. Karagouniko raw milk and cream fat were characterised by lower $\omega-6 / \omega-3$ ratio, thrombogenic index values and higher $\omega-3$ proportion compared to those of Chios breed. Therefore, the consumption of Karagouniko milk and cream may offer high nutritional benefits.

Acknowledgments We are grateful to the Department of Animal Science \& Aquaculture, of Agricultural University of Athens, for providing the milk samples. We would like to express our gratitude to Dr. Panagiotis Zoumpoulakis for valuable help with the manuscript.

Statement of human and animal rights All applicable institutional and/or national guidelines for the care and use of laboratory animals were followed. The experiments were approved by the Bioethical Committee of the Agricultural University of Athens under the guidelines of Council Directive 86/609/EEC regarding the protection of animals used for experimental and other scientific purposes. 
Conflict of interest The authors Vassilia J. Sinanoglou, Panagiota Koutsouli, Charalambos Fotakis, Georgia Sotiropoulou ${ }^{\mathrm{a}}$, Dionisis Cavouras and Iosif Bizelis have declared no conflict of interest.

\section{References}

Arnould VM-R, Soyeurt H (2009) Genetic variability of milk fatty acids. J Appl Genet 50(1):29-39

Batovska DI, Todorova IT, Tsvetkova IV, Najdenski HM (2009) Antibacterial study of the medium chain fatty acids and their 1-monoglycerides: individual effects and synergistic relationships. Pol J Microbiol 58(1): 43-47

Bhattacharya A, Banu J, Rahman M, Causey J, Fernandes G (2006) Biological effects of conjugated linoleic acids in health and disease. J Nutr Biochem 17(12):789-810

Bizelis J, Deligeorgis SG, Rogdakis E (1990) Puberty attainment and reproductive gharacteristics in ewe lambs of Chios and Karagouniko breeds raised on two planes of nutrition. Anim Repr Sci 23:197-212

Chilliard Y, Ferlay A, Rouel J, Lamberet G (2003) A review of nutritional and physiological factors affecting goat milk lipid synthesis and lipolysis. J Dairy Sci 86:1751-1770

De La Fuente LF, Barbosa E, Carriedo JA, Gonzalo C, Arenas R, Fresno JM, San Primitivo F (2009) Factors influencing variation of fatty acid content in ovine milk. J Dairy Sci 92:3791-3799

EFSA Panel on Animal Health and Welfare (AHAW) (2014) Scientific opinion on the welfare risks related to the farming of sheep for wool, meat and milk production. EFSA J 12(12):3933, doi:10.2903/j.efsa.2014. 3933

Erickson MC (1992) Variation of lipid and tocopherol composition in three strains of channel catfish (Ictalurus punctatus). J Sci Food Agric 59:529-536

FAO/WHO (2008) Expert Consultation on fats and fatty acids in human nutrition, November 10-14, 2008, WHO HQ, Geneva

Gün I, Simsek B (2011) The fatty acid composition of butter stored in sheep's or goat's stomach (Karinyagi). Food Nutr Sci 2:402-406

Haenlein GFW, Wendorff WL (2006) Sheep milk_-production and utilization of sheep milk. In: Park YW, Haenlein GFW (eds) Handbook of milk of non-bovine mammals. Blackwell Publishing Professional, Oxford, UK and Ames, Iowa, USA, pp 137-194

Hatziminaoglu J, Zervas NP, Boyazoglu J (1990) Prolific dairy sheep breeds in Greece. In: Bougler J, Tisserand $\mathrm{J}-\mathrm{L}$ (eds) Les petits ruminants et leurs productions laitières dans la région méditerranéenne. CIHEAM, Options Méditerranéennes: Série A. Séminaires Méditerranéens, Montpellier; n. 12, pp 25-30

Hopkins MJ, Macfarlane GT (2000) Evaluation of 16s rRNA and cellular fatty acid profiles as markers of human intestinal bacterial growth in the chemostat. J Appl Microbiol 89:668-677

Kominakis A, Nitter G, Fewson D, Rogdakis E (1997) Evaluation of the efficiency of alternative selection schemes and breeding objectives in dairy sheep of Greece. Anim Sci 64:453-461

Martini M, Salari F, Scolozzi C, Cecchi F, Ceriotti G, Caroli A (2006) Relations between milk genetic polymorphisms and the chemical physical and nutritional quality of sheep milk. 14th International Congress of the Mediterranean Federation of Health and Production of Ruminants (Fe.Me.S.P.Rum), July 12-15, Lugo - Santiago de Compostela, Spain Book of abstracts, p 238-243

Mierlita D, Daraban S, Lup F (2011) Effects of breed on milk fatty acid profile in dairy ewes, with particular reference to cis-9, trans-11 conjugated linoleic acid. S African Soc Anim Sci 441(3):223-231

Moioli B, Contarini G, Pariset L, Marchitelli C, Crisú A, Catillo G, Napolitano F (2012) Genetic variation of C18:1 and C18:2 isomers in sheep milk fat. Small Ruminant Res 103:187-193

Nagao K, Yanagita T (2010) Medium-chain fatty acids: functional lipids for the prevention and treatment of the metabolic syndrome. Review. Pharmacol Res 61:208-212

Nantapo CTW, Muchenje V, Hugo A (2014) Atherogenicity index and health-related fatty acids in different stages of lactation from Friesian, Jersey and Friesian $\times$ Jersey cross cow milk under a pasture-based dairy system. Food Chem 146:127-133

Naydenova N, Kaishev I, Iliev T, Mihaylova G (2014) Fatty acids profile, atherogenic and thrombogenic health indices of white brined cheese made from buffalo milk. Agr Sci Tech 6(3):352-355

Park YW, Juarez M, Ramos M, Haenlein GFW (2007) Physico-chemical characteristics of goat and sheep milk. Small Ruminant Res 68:88-113

Roca Fernandez AI, Gonzalez Rodriguez A (2012) Effect of dietary and animal factors on milk fatty acids composition of grazing dairy cows: a review. Iran J Appl Anim Sci 2(2):97-109 
Santos-Silva J, Bessa RJB, Santos-Silva F (2002) Effect of genotype, feeding system and slaughter weight on the quality of light lambs. II. Fatty acid composition of meat. Livest Prod Sci 77:187-194

Signorelli F, Contarini G, Annicchiarico G, Napolitano F, Orrù L, Catillo G, Haenlein GFW, Moioli B (2008) Breed differences in sheep milk fatty acid profiles: opportunities for sustainable use of animal genetic resources. Small Ruminant Res 78:24-31

Simopoulos AP (2008) The importance of the omega-6/omega-3 fatty acid ratio in cardiovascular disease and other chronic diseases. Exp Biol Med 233:674-688

Sinanoglou VJ, Strati IF, Bratakos SM, Proestos C, Zoumpoulakis P, Miniadis- Meimaroglou S (2013) On the combined application of Iatroscan-TLC-FID and GC-FID to identify total, neutral and polar lipids and their fatty acids extracted from foods. ISRN Chromatography, vol 2013. Article ID 859024, p 8 doi:10. 1155/2013/859024

Slačanac V, Božanić R, Hardi J, Rezessyné Szabó J, Lučan M, Krstanović V (2010) Nutritional and therapeutic value of fermented caprine milk. Int J Dairy Technol 63:171-189

Soják L, Blaško J, Kubinec R, Górová R, Addová G, Ostrovský I, Margetín M (2013) Variation among individuals, breeds, parities and milk fatty acid profile and milk yield of ewes grazed on pasture. Small Ruminant Res 109:173-181

Specht DF (1990) Probabilistic neural networks. Neural Netw 3:109-118

Strzałkowska N, Jóźwik A, Bagnicka E, Krzyżewski J, Horbańczuk K, Pyzel B, Horbańczuk JO (2009) Chemical composition, physical traits and fatty acid profile of goat milk as related to the stage of lactation. Anim Sci Pap Rep 27(4):311-320

Talpur FN, Bhanger ML, Memon NN (2009) Milk fatty acid composition of indigenous goat and ewe breeds from Sindh, Pakistan. J Food Compost Anal 22:59-64

Theodoridis S, Koutroumbas K (2008) Pattern recognition, 4th edn. Academic Press, San Diego: Elsevier.

Tsiplakou E, Mountzouris KC, Zervas G (2006) The effect of breed, stage of lactation and parity on sheep milk fat CLA content under the same feeding practices. Livest Sci 105:162-167

Ulbrich TLV, Southgate DAT (1991) Coronary heart disease seven dietary factors. Lancet 338:985-992

Vlaeminck B, Fievez V, Tamminga S, Dewhurst RJ, Van Vuuren AM, De Brabander D, Demeyer D (2006) Milk odd- and branched- chain fatty acids in relation to the rumen fermentation pattern. J Dairy Sci 89 : 3954-3964 